\title{
A novel Mcl1 variant inhibits apoptosis via increased Bim sequestration
}

\author{
Judith Hagenbuchner ${ }^{1,3}$, Ursula Kiechl-Kohlendorfer ${ }^{1}$, Petra Obexer ${ }^{1,3}$, Michael J. \\ Ausserlechner ${ }^{2,3}$ \\ ${ }^{1}$ Department of Pediatrics II, Medical University Innsbruck, Austria \\ 2 Department of Pediatrics I, Medical University Innsbruck, Austria \\ ${ }^{3}$ Tyrolean Cancer Research Institute, Innsbruck, Austria \\ Correspondence to: Petra Obexer, email: Petra.Obexer@i-med.ac.at
}

Correspondence to: Michael Ausserlechner, email: Michael.J.Ausserlechner@i-med.ac.at

Keywords: MCl1L, apoptosis, BCL2 proteins, mRNA variant

Received: July 1, $2013 \quad$ Accepted: July 13, $2013 \quad$ Published: July 15, 2013

This is an open-access article distributed under the terms of the Creative Commons Attribution License, which permits unrestricted use, distribution, and reproduction in any medium, provided the original author and source are credited.

\section{ABSTRACT:}

Members of the $\mathrm{Bcl}-2$ protein family are frequently deregulated in tumors as they critically control cell death induction in mammalian cells. Alterations of these proteins may cause resistance to chemotherapy-induced cell death and immune responses. By serendipity we cloned a variant of the anti-apoptotic Bcl2-family member Myeloid cell leukemia-1 (Mcl1) from human neuroblastoma and leukemia cells. This Mcl1L variant lacks a 45 bp sequence that codes for 15 highly conserved amino acids ranging from Gly158 to Asp172. This region is part of the so called PEST-sequence of Mcl1L and contains two phosphorylation sites (Ser159 and Thr163) that regulate Mcl1L stability. A caspase 3/caspase 8 cleavage site at Asp157 which has been reported to be critical for death-receptor-induced apoptosis and for the conversion of Mcl1L into a pro-

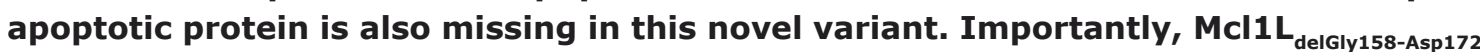
bound significantly more pro-apoptotic Bim compared to Mcl1L and showed increased anti-proliferative and anti-apoptotic activity compared to $\mathrm{Mcl} 1 \mathrm{~L}$ during death receptorinduced cell death. This suggests that this novel Mcl1L variant efficiently protects tumor cells against extrinsic death signalling and therefore may provide a survival advantage for highly aggressive tumors.

\section{INTRODUCTION}

Mcl1 was originally identified in differentiating myeloid cells [1] and has unique structural features among the members of the anti-apoptotic BCL2 family. The C-terminal part (aa 170-300) of Mcl1 shares structural similarities with other anti-apoptotic BCL2 family members, like BclxL. The N-terminal part, however, lacks the characteristic BH4 domain and instead contains two highly conserved proline, glutamic acid, serine and threonine-rich PEST sequences [2]. The second PEST sequence includes also two caspase cleavage sites (Asp127, Asp157) and several phosphorylation sites that are involved in regulating Mcl1 function and stability [3-6]. Mcl1L expression is controlled by various transcriptional, post-transcriptional and post-translational pathways downstream of growth factor- and cytokine signaling [7-9]. Thr163 is the main phosphorylation site in Mcl1 regulating stability, function and association with pro-apoptotic BH3-only proteins. ERK-mediated phosphorylation at Thr163 and Thr92 increases Mcl1stability by binding to Pin-1 [10] as well as its antiapoptotic function. Stress-induced phosphorylation on Ser121 and Thr163 inactivates Mcl1 pro-survival function $[11,12]$ and combined phosphorylation at Thr163 and Ser159 by JNK and GSK3ß destabilizes Mcll as well as reduces its interaction with pro-apoptotic Bim [13]. Beside phosphorylation the interaction with distinct $\mathrm{BH} 3-$ only proteins also coordinates Mcll expression, function and stability. Mcll can bind and thereby inactivate pro-apoptotic Bak $[14,15]$ but this complex can be either disrupted via extrinsic death signaling by tBid or intrinsically by induction of PMAIP1/Noxa, leading to proteasomal degradation of $\mathrm{Mcl} 1$ and apoptosis induction 
via Bak-oligomerisation [15-18]. Binding and inactivation of Bim and Puma increases Mcl1 levels, protects Mcl1 from degradation and acts anti-apoptotic by sequestration of Bim [17, 19, 20]. Cleavage of Mcl1 by caspase-3 or 8 during TRAIL-induced apoptosis, however, releases sequestered Bim and causes apoptosis via activation of Bax. The cleavage and inactivation of Mcl1L by caspases represents a second, Bid-independent linkage between extrinsic and intrinsic death pathway [16, 21]. Proteasomal degradation of Mcl1 is controlled by different E3-ubiquitin ligases. The most prominent is MULE, which is thought to regulate the constitutive turnover of Mcl1L by binding via its BH3-domain to the hydrophobic pocket of Mcl1L [6]. Two additional E3-ligases have been identified that regulate Mcl1L ubiquitination: During apoptosis execution and triggered by GSK3ß-induced phosphorylation of $\mathrm{Mcl1L}$ the E3-ligases $\mathrm{SCF}^{\mathrm{FBW} 7}$ and $\beta$-TRCP regulate $\mathrm{Mcl1}$ degradation $[22,23]$. The activity of these E3-ligases is counteracted by the de-ubiquitinase USP9X which removes Lys48-linked polyubiquitine-chains and thereby stabilizes Mcl1L and increases its anti-apoptotic function $[18,24]$.

Beside anti-apoptotic full-length $\mathrm{Mcl1L}$, there is evidence for several pro-apoptotic Mcl1 variants. Proapoptotic variants are generated either by cleavage of Mcl1 by caspase- 3 or $8[25,26]$ or by alternative splicing. Loss of exon 2 results in the translation of Mcl1s (short, 271aa), a splice variant which only contains the $\mathrm{BH} 3$-domain and inactivates $\mathrm{Mcl} 1 \mathrm{~L}$ thereby acting like a pro-apoptotic $\mathrm{BH} 3$-only protein $[27,28]$. Such a pro-apoptotic variant is also known for BclxL, where alternative splicing generates BclxS [29]. Splicing in exon1, at a non-canonical splice site, leads to Mcl1ES (extra short, 197 aa), which lacks the PEST sequence but binds Mcl1L. This variant does not sequester Bax or Bak and thereby acts pro-apoptotic [30]. In the present study we characterized a novel Mcll splice variant, which was cloned from human neuroblastoma and leukemia cells. As this variant lacks important regulatory parts of the PEST sequence we hypothesized that tumor cells expressing this Mcll variant may gain survival advantages and escape certain death stimuli.

\section{RESULTS}

\section{Cloning of a novel variant of human Mcl1 in human cancer cells.}

In the course of PCR analyses of Mcl1 mRNA variants in human neuroblastoma cells we amplified an mRNA species that carries a 45 bp deletion in the Mcl1L coding region from SH-EP neuroblastoma cells. For simplicity we termed this $\mathrm{Mcl1L}_{\text {del158-172 }}$ variant $\mathrm{Mcl1}_{\text {JAM }}$ (Just Another Mcl1). PCR-products corresponding to the full length and the $\mathrm{Mcl1}_{\mathrm{JAM}}$ variant were detected also in a CEM leukemia cell line (Fig. 1A). The shortened Mcl1 variant lacks a 15 amino acids region ranging from Gly 158 to Asp172 that contains a caspase $3 / 8$ cleavage site and the two important regulatory amino acids Ser159 and Thr163 (Fig. 1B). This part of Mcl1 is highly conserved within mammals (Fig. 1C). The phosphorylation of Mcl1L on Ser159 and Thr163 by GSK3 $\beta$, ERK or JNK is critical for Mcl1 stability and its interaction with pro-apoptotic BH3only proteins [13].

The region Gly158 to Asp172 is the most prolineand glutamate-rich part of the PEST region which acts as a signal sequence for proteasomal degradation and determines the short protein half-life of Mcl1. As the functional consequences of lack of this region are unclear, we next investigated how the function of $\mathrm{Mcl}_{1} \mathrm{~L}_{\mathrm{JAM}}$ differs from Mcl1L and if this novel variant affects the physiology and death resistance of human neuroblastoma cells.

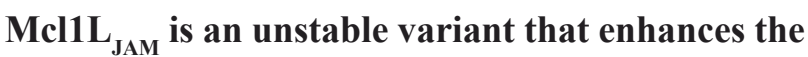 anti-proliferative effect of Mcl1L.}

Besides playing a key role in the regulation of mitochondrial cell death Mcl1L and the recently described proteolytic fragment snMcl1 were also implicated in the regulation of cell cycle progression. Mcl1L binds to PCNA in the nucleus and thereby inhibits proliferation, whereas snMcl1 reduces CDK1 activity [31, 32]. To assess whether $\mathrm{Mcl1}_{\mathrm{JAM}}$ differs in its anti-proliferative activity from full length Mcl1L SH-EP cells were infected with a retrovirus vector containing either the coding sequence for $\mathrm{Mcl} 1 \mathrm{~L}$ full-length or the mRNA variant $\mathrm{Mcl}_{1} \mathrm{~L}_{\mathrm{JAM}}$. The expression of the smaller variant was verified by immunoblot in presence or absence of the proteasome inhibitor Bortezomib. Similar to Mcl1L Bortezomib treatment led to accumulation of the variant $\mathrm{Mcll}_{\mathrm{JAM}}$ suggesting that despite its truncated PEST sequence, $\mathrm{Mcl1}_{\text {JAM }}$ is still degraded via the proteasome (Fig. 2A). Ectopic Mcl1L expression reduced the colony forming capacity of SH-EP neuroblastoma cells to $74.4 \%$ compared to mock-infected controls $(100 \%)$ but did not influence the colony size (Fig. 2B). Ectopic Mcl1L $\mathrm{J}_{\mathrm{JAM}}$ expression, however, further reduced the number of colonies to $66 \%$ compared to $\mathrm{SH}$ $\mathrm{EP} / \mathrm{Ctr}$ cells and also interestingly reduced colony size (Fig. 2B). This suggests that $\mathrm{Mcl}_{1} \mathrm{~L}_{\mathrm{JAM}}$ reduces the ability of single cells to form colonies and, in contrast to Mcl1L, also reduces colony size suggesting a more pronounced anti-proliferative effect of this variant.

\section{Lack of Gly158 to Asp172 reduces protein stability.}

Mcl1L function, interactions and degradation are critically regulated by phosphorylation of Ser159 and Thr163 within the PEST region (reviewed in [33]). As $\mathrm{Mcl}_{1} \mathrm{~L}_{\mathrm{JAM}}$ exerted enhanced anti-proliferative activity 
compared to Mcl1L and lacks the region containing several proline and glutamate amino acids and these two important phosphorylation sites we hypothesized that $\mathrm{Mcl1L}_{\mathrm{JAM}}$ may have an altered half-life compared to Mcl1L. We therefore analysed phosphorylation at Ser159 and Thr163 during bortezomib treatment. In cells ectopically expressing $\mathrm{Mcl} 1 \mathrm{~L}$ the inhibition of proteasome-mediated protein degradation resulted in significant accumulation of $\mathrm{Mcl1L}$ phosphorylated at Ser159/Thr163. This implies that in control cells Ser159/Thr163 are phosphorylated and $\mathrm{Mcl1L}$ is subject to permanent turnover. Interestingly, the Bortezomib-treatment of neuroblastoma cells overexpressing $\mathrm{Mcl}_{\mathrm{JAM}} \mathrm{L}_{\mathrm{JM}}$ mainly resulted in accumulation of this novel variant, whereas the endogenous Mcl1L remained unphosphorylated and only slightly accumulated. This suggests that despite truncation of the PEST sequence, $\mathrm{Mcl1}_{\mathrm{JAM}}$ competes with endogenous Mcl1L for binding partners that mediate the degradation of Mcl1 (Fig.3A). Next we analysed possible differences between protein half-life of $\mathrm{Mcl1L}$ and $\mathrm{McllL}_{\mathrm{JAM}}$ by treating the Mcl1L or $\mathrm{Mcl1}_{\mathrm{JAM}}$-expressing cells with 10 $\mu \mathrm{g} / \mathrm{ml}$ cycloheximide (CHX) for up to 3 hours. In SH-EP/ Ctr cells endogenous Mcl1L steady state expression is already significantly lowered within 30 minutes of $\mathrm{CHX}$ treatment to about $50 \%$ (Fig.3B, upper panel). Similar results were obtained for cells expressing ectopic Mcl1L with about $67 \%$ of Mcl1L being present after $30 \mathrm{~min}$. The higher amounts of Mcl1L in the overexpression system compared to endogenous Mcl1L suggests that the $\mathrm{CHX}$ block of translation was not $100 \%$ complete (Fig.3B, lower panel). Despite the shortened PEST sequence overexpressed $\mathrm{Mcl1}_{\mathrm{JAM}}$ had a slightly lower stability than overexpressed Mcl1L (49\% versus $67 \%$ after $30 \mathrm{~min}$ ) with a rapid decay after $60 \mathrm{~min}(12 \%$ versus $34 \%)$ and $90 \mathrm{~min}$ ( $7 \%$ versus $23 \%$ ). However, the expression of $\mathrm{Mcl}_{1} \mathrm{~L}_{\mathrm{JAM}}$ stabilized endogenous Mcl1L and significantly increased the half-life of endogenous Mcl1L to $93 \%$ after $30 \mathrm{~min}$ and still 47\% after one hour (Fig. 3B, right panel). This suggests that the variant $\mathrm{Mcl1}_{\mathrm{JAM}}$ has a short half-life but protects Mcl1L from proteasomal degradation causing its stabilization and may therefore directly and/or indirectly affect apoptosis sensitivity.

\section{Lack of Gly158 to Asp172 increases steady state expression of pro-apoptotic Bim.}

Phosphorylation at Ser159 and Thr163 not only induces destabilization of Mcl1L but was also reported to decrease the ability of $\mathrm{Mcl} 1 \mathrm{~L}$ to bind and inactivate pro-apoptotic protein Bim [13]. We therefore next studied how deletion of the region Gly158 to Asp172 in Mcl1L

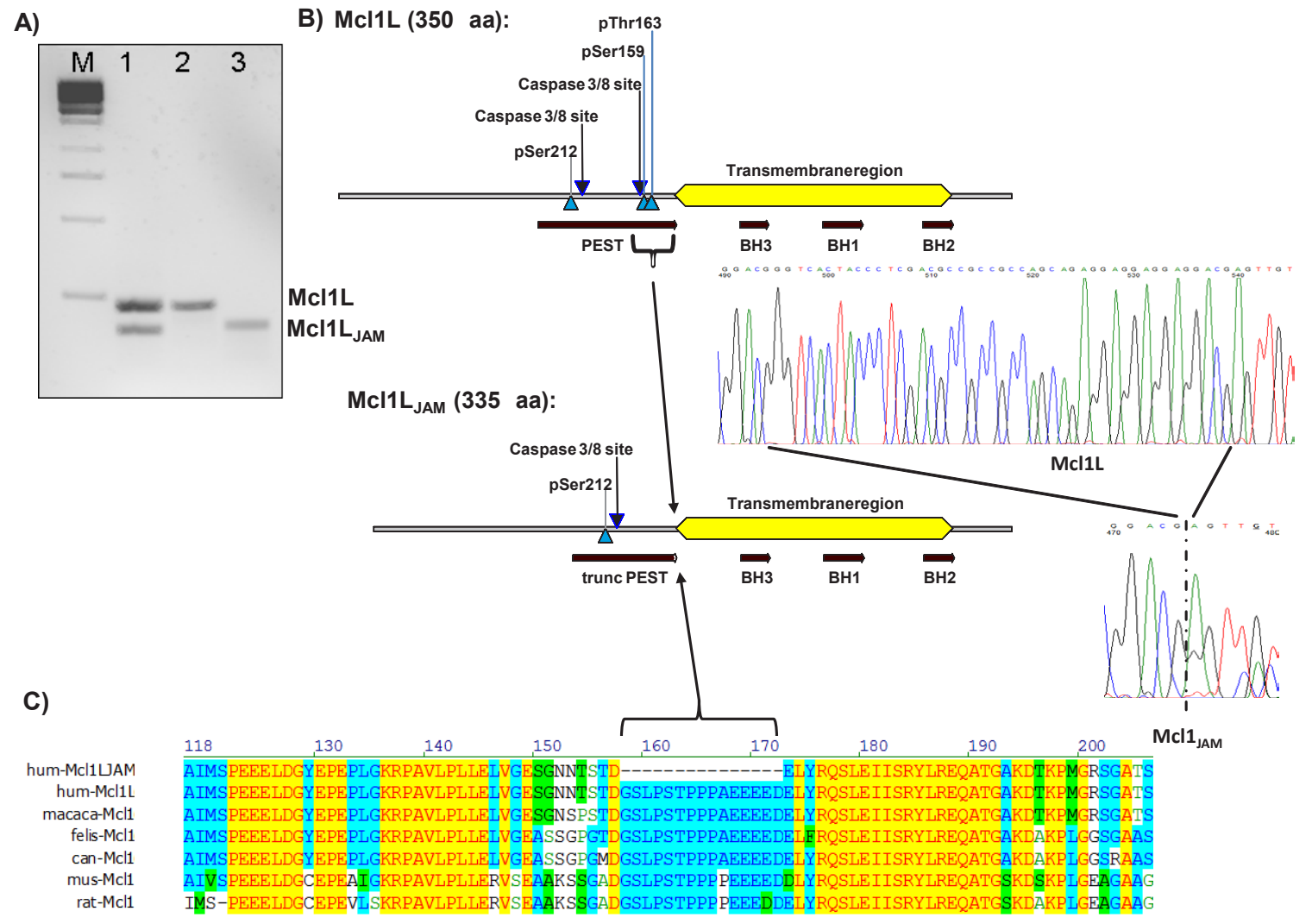

Figure 1: Cloning of a novel mRNA variant of Mcl1L. Nested PCR of cDNA from C7H2 leukemia cells (lane 1). Expression vectors for either Mcl1L or $\mathrm{Mcll}_{\mathrm{JAM}}$ were used as positive controls (lane 2 and 3). $\mathrm{Mcl}_{1} \mathrm{~L}_{\mathrm{JAM}}$ lacks 45 bp within the coding region of Mcl1L mRNA which codes for the amino acids Gly158 to Asp172. These 15 amino acids are part of the PEST sequence of MCL1L (b) which is highly conserved within different mammalian species (c). 
might affect expression and interaction with pro-apoptotic Mcl1L-binding partners. Overexpression of $\mathrm{Mcl1L}$ is associated with elevated steady state protein levels of Noxa, which can be further increased by Bortezomibtreatment (Fig.3C). This suggests that increased levels of anti-apoptotic Mcl1L sequester higher amounts of the pro-apoptotic binding partner Noxa and thereby allow a cell to cope with increased cellular levels of cell death inducers. Interestingly $\mathrm{SH}-\mathrm{EP} / \mathrm{Mcl1L}_{\mathrm{JAM}}$ cells did not contain elevated Noxa-levels, although Bortezomibtreatment increased Noxa steady state levels similar to SH-EP/Mcl1L cells (Fig.3C). Mcl1L $\mathrm{J}_{\mathrm{JAM}}$ overexpression instead clearly increased basal Bim levels compared to $\mathrm{SH}-\mathrm{EP} / \mathrm{Mcl1L}$ or $\mathrm{SH}-\mathrm{EP} / \mathrm{Ctr}$ cells, suggesting that $\mathrm{Mcl1}_{\mathrm{JAM}}$ may efficiently prevent the death-inducing effect of Bim, possibly by sequestration. These $\mathrm{Mcl1}_{\mathrm{JAM}}$ -specific changes in the steady state expression of Noxa

A)

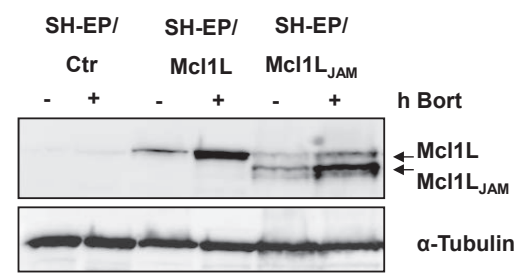

B)
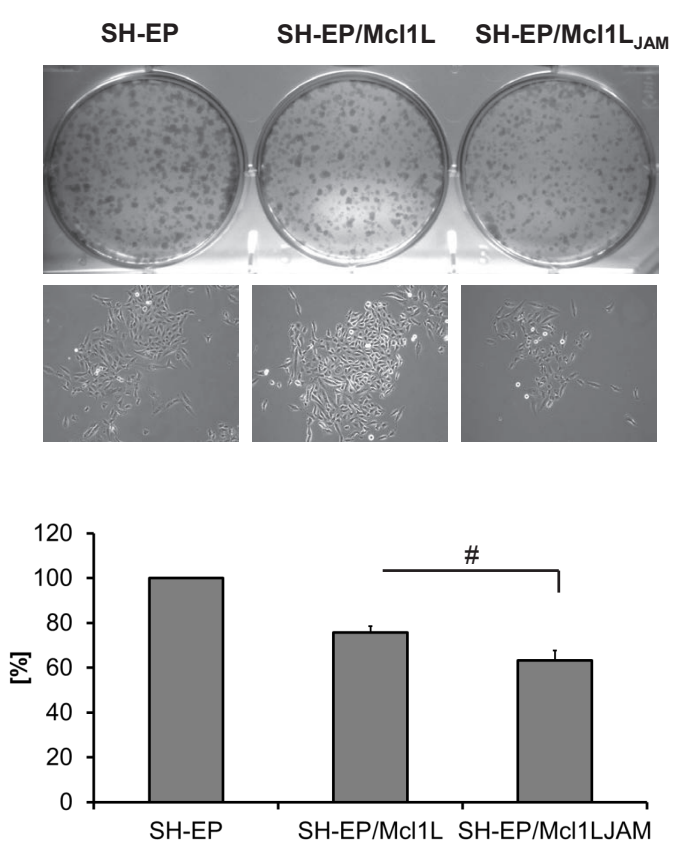

Figure 2: The Mcl1L mRNA variant $M_{\text {cl1 }} \mathrm{L}_{\mathrm{JAM}}$ exerts anti-proliferative effect. SH-EP/Ctr, SH-EP/McllL and $\mathrm{SH}-\mathrm{EP} / \mathrm{Mcl1L}_{\mathrm{JAM}}$ cells were treated for four hours with $200 \mathrm{nM}$ bortezomib (bort). Cell lysates were subjected to immune blot to verify ectopic expression of $\mathrm{Mcl} 1 \mathrm{~L}$ and $\mathrm{Mcl}_{\mathrm{JAM}} \cdot \alpha$-Tubulin served as a loading control (a). Colony formation was analysed by crystal violet staining of $2 \times 10^{3} \mathrm{SH}-\mathrm{EP} / \mathrm{Ctr}$, SH-EP/Mcl1L and $\mathrm{SH}-\mathrm{EP} / \mathrm{Mcll}_{\mathrm{JAM}}$ cells after 7 days cultivation (b, upper and lower panel). Bright field analyses of single colonies were performed in an Axiovert200M microscope (b, middle panel). Shown is the mean of four independent experiments. Statistical analysis was performed using students t-test $(* \mathrm{P}<0.05)$. and Bim are also observed, when Mcl1L or $\mathrm{Mcl1}_{\mathrm{JAM}}$ are expressed in leukaemia cell lines (Supplemental figure S2), suggesting that the specific accumulation of Noxa or Bim depends on structural characteristics of Mcl1L and $\mathrm{Mcl1}_{\mathrm{JAM}}$, respectively. To study whether the increased expression levels correlate with an increased interaction of these proteins, we generated cells with tetracyclineinducible expression of Noxa or Bim and constitutively expressed ECFP-tagged Mcl1L (ECFP-Mcl1L) or EYFPtagged $\mathrm{Mcl1}_{\mathrm{JAM}}\left(\mathrm{EYFP}-\mathrm{Mcl1}_{\mathrm{JAM}}\right)$. Treatment of SHEP/tetNoxa-ECFP-Mcl1L cells with doxycyline (doxy) induces Noxa expression (Fig. 4B, lane 2) but also increased the ECFP-Mcl1L signal (Fig. 4A) and ECFPMcl1L steady state expression as measured by immunoblot (Fig. 4B). This suggests that increased levels of Noxa lead to the accumulation of more stable Noxa/Mcl1L complex in neuroblastoma cells [34]. A possible explanation for this stabilization might be that Noxa binds into the BH3domain of Mcl1L displaces the ubiquitine-ligase MULE from Mcl1L and thereby reduces Mcl1L turn over [35, 36].

In contrast, doxycycline-induced expression of Noxa in SH-EP/tetNoxa-EYFP- Mcl1L $\mathrm{L}_{\mathrm{JAM}}$ cells did not increase the fluorescence intensity or protein steady state levels of ECFP- Mcl1L $_{\text {JAM }}$ although Noxa still elevated protein levels of endogenous Mcl1L (Fig. 4C). Co-immunoprecipiation experiments of Noxa revealed that in SH-EP/tetNoxa-ECFP-Mcl1L cells endogenous Mcl1L and ECFP-Mcl1L precipitated with Noxa, with increased amounts when Mcll degradation is blocked by proteasome inhibition (Fig. 4B). Since BclxL is also an interaction partner of Noxa in neuroblastoma cells [34], we also analysed BclxL in Noxa-precipitates and found low amounts of BclxL bound to Noxa in McllLoverexpressing cells (Fig.4B). This suggests a basal interaction of BclxL and Noxa and if Noxa expression is further elevated part of Noxa is sequestered by Mcl1L. In contrast, in SH-EP/tetNoxa-EYFP-Mcl1 $\mathrm{L}_{\mathrm{JAM}}$ cells only small amounts of EYFP-Mcl1L $\mathrm{L}_{\text {JAM }}$ precipitated with Noxa, whereas endogenous Mcl1L binds to Noxa in the same manner as in ECFP-Mcl1L-overexpressing cells. In these cells, however, significantly increased amounts of BclxL co-purified with Noxa (Fig. 4D). This suggests that Noxa interacts with BclxL and Mcl1L at higher affinity than with $\mathrm{Mcl1}_{\mathrm{JAM}}$.

In SH-EP/tetBim-EYFP-Mcl1 $\mathrm{L}_{\mathrm{JAM}}$ and SH-EP/ tetBim-ECFP-Mcl1L Bim-induction (doxy-treatment) increased steady state levels of $\mathrm{Mcl}_{\mathrm{JAM}}$ and $\mathrm{Mcl} 1 \mathrm{~L}$ which is in line with results from Wuillème-Toumi et al, who found that Bim and Mcl1L protect each other from degradation [20]. By co-immunoprecipitation experiments we found that Bim interacted with endogenous $\mathrm{Mcl1L}$, ECFP-Mcl1L and BclxL which similar affinity, suggesting that increased Bim amounts equally distribute between Mcl1L and BclxL (Fig. 5B). In SH-EP/tetBim-EYFP$\mathrm{Mcl1}_{\mathrm{JAM}}$ cells, doxy-induced Bim precipitated EYFP$\mathrm{Mcll}_{\mathrm{JAM}}$ and to a lesser extend endogenous Mcl1L. 
Co-purification of BclxL was only observed in cells treated with both, doxy and bortezomib (Fig. 5D). This combined effect may be due to the fact that bortezomib further induces Noxa, which partially sequesters Mcl1L and BclxL in neuroblastoma cells [34]. The combined data suggest that $\mathrm{Mcll}_{\mathrm{JAM}}$ efficiently binds and inactivates Bim and thereby changes the interaction of this proapoptotic protein with other $\mathrm{Bcl} 2$ proteins. In the next step we therefore analysed whether $\mathrm{Mcl1}_{\mathrm{JAM}}$ expression changes the sensitivity to distinct apoptosis-stimuli of extrinsic and intrinsic apoptosis signalling.

\section{Increased expression of $\mathrm{Mcl}_{1} \mathrm{~L}_{\mathrm{JAM}}$ protects neuroblastoma cells against death receptor- mediated apoptotic cell death.}

SH-EP/Ctr, SH-EP/Mcl1L or SH-EP/Mcl1L $\mathrm{L}_{\mathrm{JAM}}$ cells were treated either with the chemotherapeutics etoposide and doxorubicin that are expected to mainly trigger the intrinsic apoptotic pathway or with FASL/ CH11 or TRAIL to induce apoptosis via death receptors. Interestingly, both $\mathrm{Mcl1} 1 \mathrm{~L}$ and $\mathrm{Mcl1L}_{\mathrm{JAM}}$ only inhibited FASL- and TRAIL-induced apoptosis (Fig.6AB), whereas they failed to rescue neuroblastoma and leukemia cells from etoposide or doxorubicin-induced cell death (Figure $6 \mathrm{C}$ and Supplemental figure $1 \mathrm{AB}$ ). $\mathrm{Mcl1}_{\mathrm{JAM}}$ expression

\section{A)}

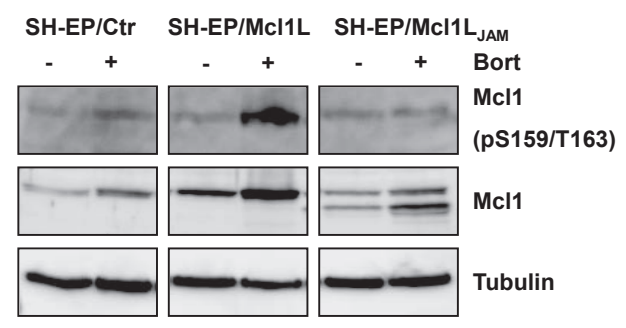

B)
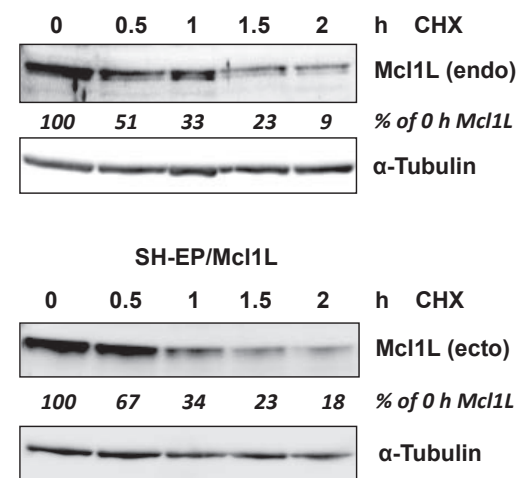

significantly reduced cell death from $48.8 \%$ to $18.8 \%$ after TRAIL treatment and from $23.3 \%$ to $3.6 \%$ after $\mathrm{CH} 11$ treatment. $\mathrm{Mcl}_{\mathrm{JAM}}$ thereby induced significantly higher death resistance than $\mathrm{Mcl1L}$ overexpression after 48 hours $(\mathrm{P}<0.05)$. To study long-term survival after treatment we performed clonogenic survival assays which demonstrated that survival of neuroblastoma cells after FAS-receptor activation by $\mathrm{CH} 11$ antibody was significantly increased in $\mathrm{Mcl1L}_{\mathrm{JAM}}$-expressing cells $(201 \%, \mathrm{P}<0.01)$ compared to Mcl1L-expressing cells (143\%) and SH-EP/Ctr cells (Fig.6C). However, no significant differences were detectable in etoposide or doxorubicin treated cells (Fig.6C). Taken together, these data suggest that deletion of the sequence Gly158 to Asp172 in $\mathrm{Mcl1L}_{\text {JAM }}$ confers increased resistance to death receptor-induced apoptosis and thereby may provide a survival advantage for tumor cells.

\section{DISCUSSION}

In the present study we functionally analysed the novel Mcl1L mRNA variant $\mathrm{Mcl}_{1} \mathrm{~L}_{\text {delGly158-Asp172 }}$ which we named $\mathrm{Mcll}_{\mathrm{JAM}}$. This variant was cloned by serendipity from human neuroblastoma and leukemia cells and lacks a 15 amino acids region (Gly158-Asp172) including a caspase $3 / 8$ cleavage site and two regulatory amino acids (Ser159, Thr163). Both, Mcl1L and $\mathrm{Mcl1L}_{\mathrm{JAM}}$

C)

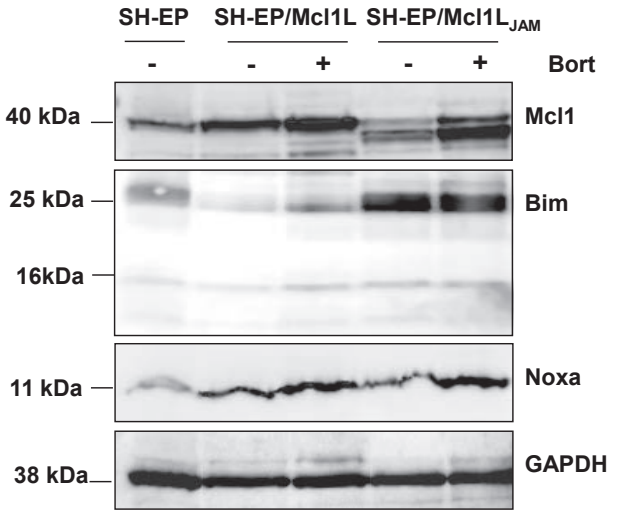

Figure 3: Mcl1L $_{\mathrm{JAM}}$ rescues Mcl1L from degradation and cooperates with $\mathrm{Bim}$. SH-EP/Ctr, SH-EP/Mcl1L and SH-EP/ $\mathrm{Mcl1L}_{\mathrm{JAM}}$ cell lysates were analysed for phosphorylated Mcl1 (Ser159/Thr163) and Mcl1 after treatment with bortezomib for four hours (a). $\alpha$-Tubulin served as loading control. Protein stability was analysed by treating SH-EP/Ctr, SH-EP/Mcl1L or SH-EP/Mcl1L $\mathrm{L}_{\mathrm{JAM}}$ cells with $10 \mu \mathrm{g} / \mathrm{ml} \mathrm{CHX}$ for the times indicated (b). $\alpha$-Tubulin served as loading control. SH-EP/Ctr, SH-EP/Mcl1L and SH-EP/Mcl1L $\mathrm{L}_{\mathrm{JAM}}$ cells were treated for four hours with $200 \mathrm{nM}$ bortezomib. Cell lysates were analysed for the expression of Noxa and Bim. GAPDH served as loading control (c). 
accumulate after proteasome inhibition by bortezomib treatment (Fig.3A), suggesting that the lack of the sequence Gly158 to Asp172, although being a critical part of the PEST sequence does not prevent proteasomal degradation. Three ubiquitin ligases have been shown to control degradation of Mcl1: $\beta-\mathrm{TrCP}$ and $\mathrm{SCF}^{\mathrm{FBW} 7}$ both require phosphorylation at Ser159 and Thr163 for Mcl1 recognition/degradation via the proteasome, which makes it unlikely that these two E3-ligases also regulate the turnover of $\mathrm{Mcll}_{\mathrm{JAM}}$. In contrast the ubiquitin ligase MULE/ARF-BP1 which specifically binds to Mcl1L via its BH3-domain might be a possible candidate, especially as protein levels of $\mathrm{Mcl} 1 \mathrm{~L}$ and $\mathrm{Mcl1}_{\mathrm{JAM}}$ were affected by conditional expression of $\mathrm{BH} 3$-only proteins Noxa and Bim, respectively $[6,22,23]$. Bortezomib-treatment not only caused Mcl1L accumulation, but Mcl1L was also strongly phosphorylated at Ser159 and Thr163 (Fig.3A), suggesting that the upstream kinase cascades that modulate Mcl1L activity and stability via Ser159/Thr163 phosphorylation are active in these neuroblastoma cells.

A)

SH-EP/tetNoxa-ECFP-Mcl1L
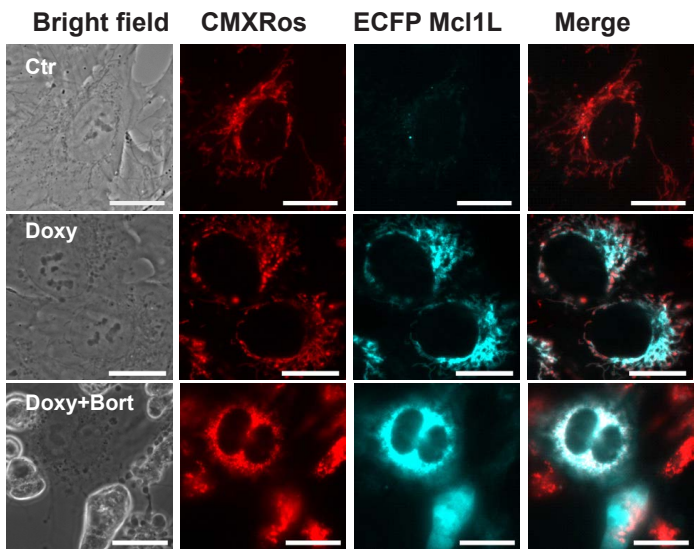

C)

SH-EP/tetNoxa-EYFP-Mcl1 $L_{\text {JAM }}$
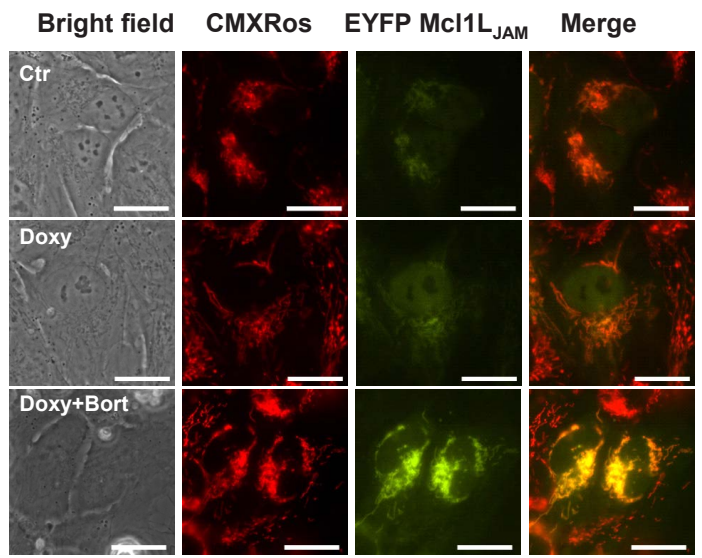

The loss of the phosphorylation site at Thr163 suggests altered stability and function of $\mathrm{Mcll}_{\mathrm{JAM}}$ compared to full length Mcl1L since phosphorylation at Thr163 represents the main regulatory phosphorylation site in Mcl1L [33]. Combined phosphorylation at Thr163 und Thr92 through ERK-1 increases Mcl1 stability through association with Pin-1 [10] whereas phosphorylation at Thr163 together with Ser159 by JNK and GSK-3ß decreases Mcll stability as well as binding to Bim [12, 13]. Actually $\mathrm{Mcl1}_{\mathrm{JAM}}$ even showed reduced stability during CHX treatment (Fig.3B) compared to Mcl1L. Ectopic $\mathrm{Mcl}_{1} \mathrm{~L}_{\mathrm{JAM}}$ disappeared almost completely after 1 hour (12\%) whereas ectopic Mcl1L showed a similar decay as endogenous Mcl1L during CHX treatment. This is in line with a recent report from Thomas et al, who demonstrated that mutation at Ser162 reduces the stability of Mcl1 [37]. Surprisingly, ectopic expression of $\mathrm{Mcl1L}_{\text {JAM }}$ enhances the half-life of endogenous Mcl1L suggesting that both proteins compete for the same binding partners and $\mathrm{Mcll}_{\mathrm{JAM}}$ is preferentially targeted for degradation

B)

SH-EP/tetNoxa-ECFP-Mcl1L

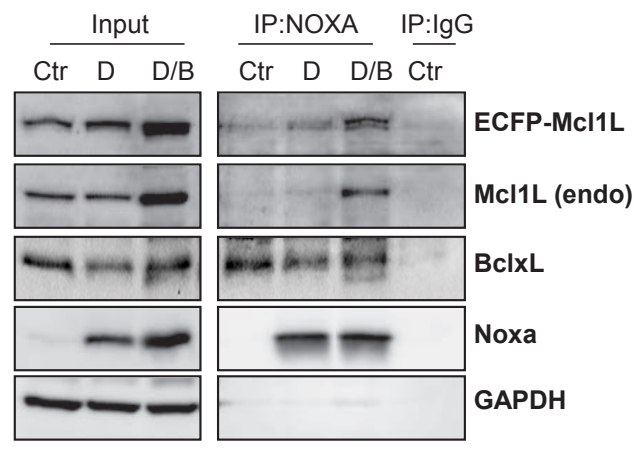

D)

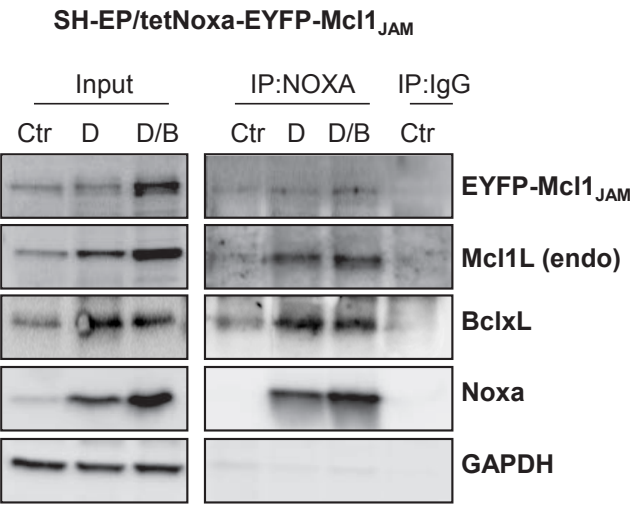

Figure 4: Mcl1L, but not Mcl1LJAM, inactivates Noxa. SH-EP/tetNoxa-ECFP-Mcl1L or SH-EP/tetNoxa-EYFP- Mcl1L ${ }_{J A M}$ cells were treated with $200 \mathrm{ng} / \mathrm{ml}$ dox(D), or with a combination of $200 \mathrm{ng} / \mathrm{ml}$ doxy and $200 \mathrm{nM}$ bortezomib (D/B) for 4 hours. Cells were either subjected to live-cell microscopy $(\mathrm{a}, \mathrm{c})$ or co-immunoprecipiation $(\mathrm{b}, \mathrm{d})$. For live cell imaging, mitochondria were stained with $300 \mathrm{nM}$ CMXRos (bar=10 $\mu \mathrm{m})$. After precipitation of Noxa, immunoblots were performed against Noxa, Mcl1, GFP, BclxL or GAPDH. Mouseserum was used as precipitation control $(\operatorname{IgG})(b, d)$. 
and therefore more instable than the wild type. Since no ubiquitin residues are affected by the deletion in $\mathrm{Mcl1}_{\mathrm{JAM}}$ (Lys5, 40, 136, 194 and 197) [6] we hypothesize that the degradation may be caused by changes in the C-terminus of $\mathrm{Mcl1}_{\mathrm{JAM}}$, which might affect binding to BH3-only proteins, for example Puma which was shown to protect Mcl1L from MULE induced degradation by binding to its BH1 domain, [36] or Bim-interaction [20]. So expression of the shortened variant may protect wild type Mcl1L from its degradation, which is likely to provide a survival advantage to $\mathrm{Mcll}_{\mathrm{JAM}}$-expressing cancer cells. We also observed this enhanced stability of Mcl1L when coexpressed with $\mathrm{Mcl1L}_{\mathrm{JAM}}$ after treatment with $\mathrm{CH} 11$ or TRAIL. Mcl1L $\mathrm{JAM}_{\text {JA }}$ was degraded after CH11 and TRAIL treatment but delayed phosphorlation and degradation of Mcl1L (Supplemental figure S3). The elevated apoptosis inhibitory function of $\mathrm{Mcl}^{1} \mathrm{~L}_{\mathrm{JAM}}$ was limited to extrinsic death signaling, as both $\mathrm{Mcl} 1 \mathrm{~L}$ and $\mathrm{Mcll}_{\mathrm{JAM}}$ failed to reduce cell death induced by etoposide and doxorubicin treatment (Fig. 6C and supplemental figure S1). In SH-

A)

SH-EP/tetBim-ECFP-Mcl1L
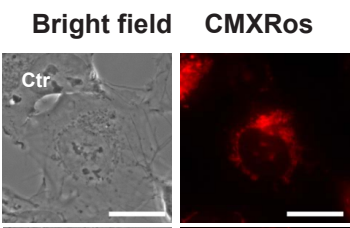

ECFP Mcl1L
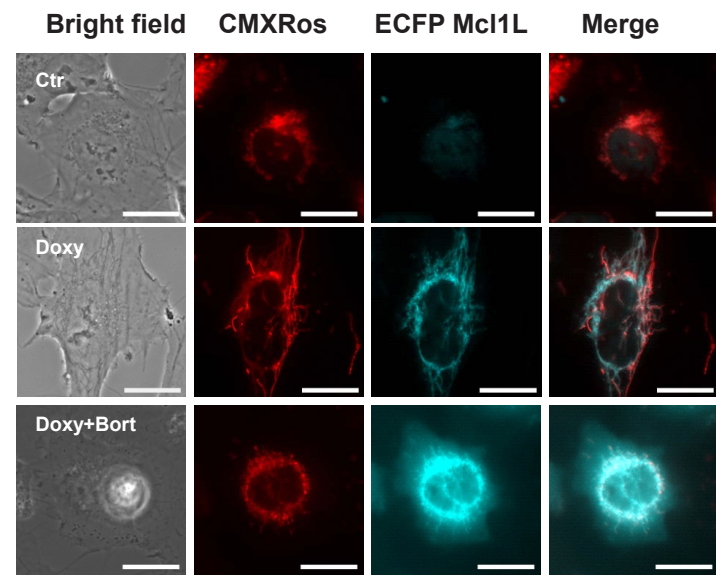

C)
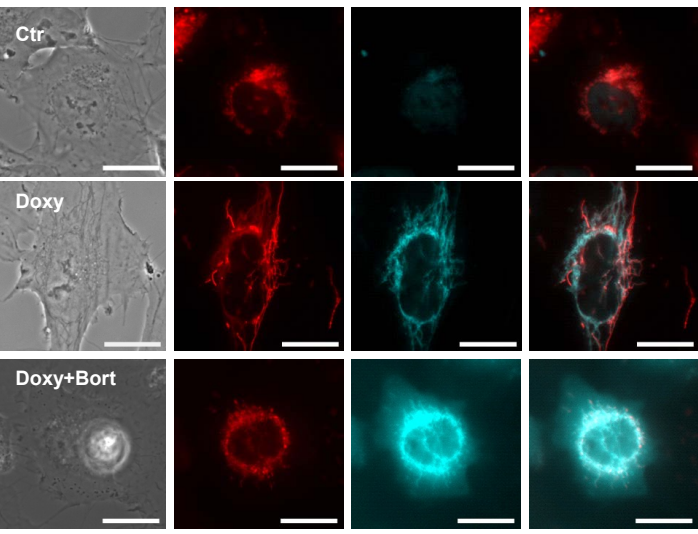

SH-EP/tetBim-EYFP-Mcl1 $L_{\text {JAM }}$

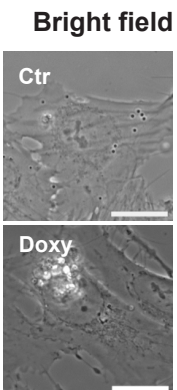

CMXRos
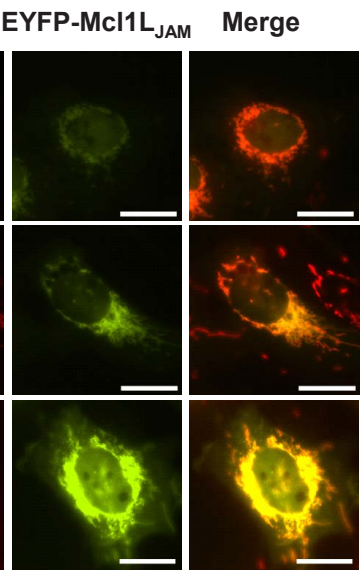

EP neuroblastoma cells efficient death receptor signalling requires involvement of mitochondria [38]. Our data suggest that the $\mathrm{Mcl}_{1} \mathrm{~L}_{\mathrm{JAM}}$ variant specifically interferes with the connection between extrinsic and intrinsic death signaling. Once caspase- 8 is activated, it may directly cleave Mcl1L at Asp157 leading to its conversion into a pro-apoptotic Bcl2-protein [39] and to changes in the sequestration of pro-apoptotic Bcl2 proteins [21]. Since $\mathrm{Mcl1L}_{\mathrm{JAM}}$ lacks Gly158, it may be protected from cleavage. Additionally caspase- 8 cleaves and activates Bid, a strong $\mathrm{BH} 3$-only protein that neutralizes Mcl1L. Since $\mathrm{Mcl}_{1} \mathrm{~L}_{\text {JAM }}$ showed increased affinity to Bim compared to Mcl1L (Fig. 4 and Fig. 5), tBid may not be able to disrupt $\mathrm{Mcl1}_{\mathrm{JAM}}{ }^{\prime}$ Bim complexes, resulting in prolonged inactivation of Bim in $\mathrm{Mcl1}_{\mathrm{JAM}}$-expressing cells. Deletion of the entire $\mathrm{Mcl} 1 \mathrm{~L}$ $\mathrm{N}$-terminus changes the $\mathrm{C}$-terminal part in a way that an increased binding with Bim is observed [21]. Interestingly, the same is also true for the short 15 amino acid deletion present in $\mathrm{Mcl1}_{\mathrm{JAM}}$ (Fig. 5B) suggesting conformational changes in the $\mathrm{C}$-terminal part of this protein variant

B)

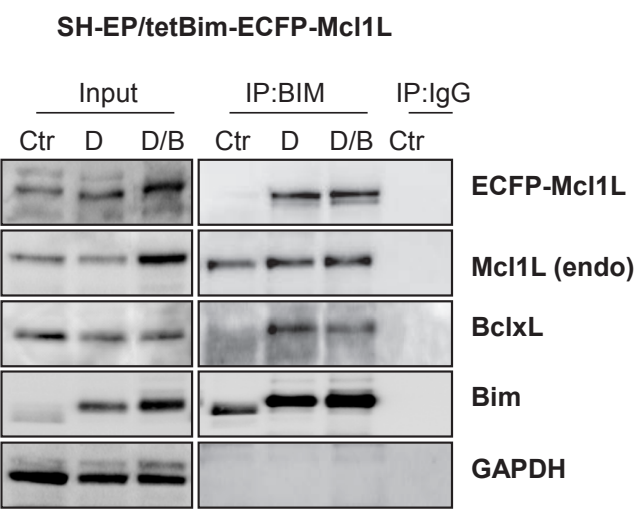

D)

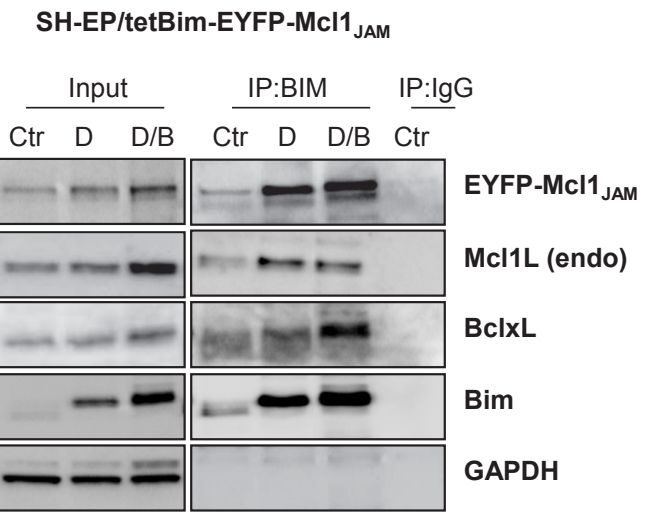

Figure 5: Mcl1LJAM interacts preferentially with Bim. SH-EP/tetBim-ECFP-Mcl1L or SH-EP/tetBim-EYFP- Mcl1L $\mathrm{JAM}_{\mathrm{J}}$ cells were treated with $200 \mathrm{ng} / \mathrm{ml}$ doxy(D) to induce Bim, or with a combination of $200 \mathrm{ng} / \mathrm{ml}$ doxy and $200 \mathrm{nM}$ bortezomib (D/B) for 4 hours. For live-cell imaging, cells were analysed after CMXRos (300 nM) staining of mitochondria (a). Bar represents $10 \mu \mathrm{m}$. After precipitation of Bim, immunoblots were performed against Bim, Mcl1, GFP, BclxL or GAPDH. Rabbit-serum was used as precipitation control (IgG) $(b, d)$. 
that result in altered hydrophobic $\mathrm{BH} 3$ binding [2]. Consistent with this hypothesis $\mathrm{Mcll}_{\mathrm{JAM}}$ completely failed to sequestrate increased cellular Noxa amounts upon tetracycline-regulated Noxa induction, (Fig. 4D). Instead, Noxa mainly interacted with endogenous BclxL and Mcl1L (Fig 4B). This suggests that Noxa binds with low affinity to $\mathrm{Mcll}_{\mathrm{JAM}}$ in neuroblastoma cells, whereas Bim is efficiently sequestrated by this variant.

A current study by Thomas et al identified Ser162 as key phosphorylation site regulating Mcll cellular localization. If this site is mutated $\mathrm{Mcl} 1 \mathrm{~L}$ almost exclusively localizes to the nucleus [37]. These changes in Mcl1 localization also lead to reduced stability and less apoptosis protection against mitochondria-induced cell death. Life cell imaging analyses of SH-EP cells infected with the EYFP-Mcl1L $\mathrm{L}_{\text {JAM }}$ construct uncovered a partial nuclear localization after stabilization of the protein with bortezomib (Supplemental figure S4, upper panel). Subcellular fragmentation experiments also detected large amounts of EYFP-tagged Mclljh in the nuclear extracts, also in untreated cells, whereas a small amount of endogenous Mcl1L was also detected in the nucleus after

A)

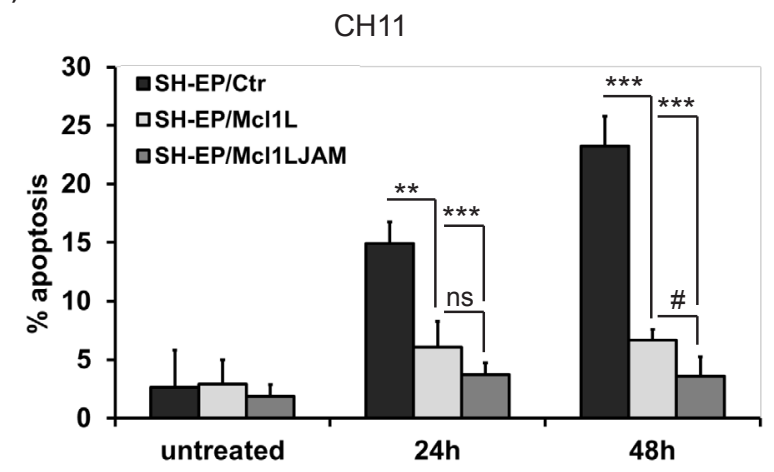

B)

TRAIL

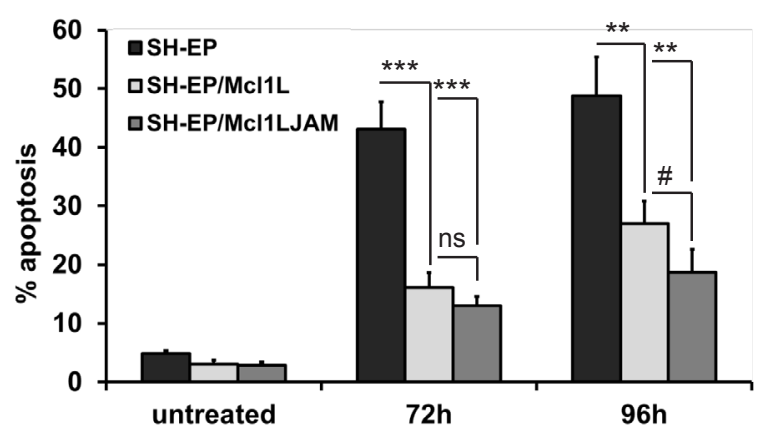

proteasome-inhibition (Supplemental figure S4, lower panel). In line with this report, $\mathrm{Mcl1}_{\mathrm{JAM}}$ was not able to inhibit mitochondrial cell death, but increases resistance to death receptor induced apoptosis (Fig 6ABC). This suggests that loss of this short peptide sequence in Mcl1 significantly affects stability, interaction with $\mathrm{BH} 3$-only proteins and also death sensitivity to distinct apoptotic signals. Expression of this Mcl1 variant may therefore represent an adaption of tumor cells to avoid extrinsic death signaling and may thereby serve as a diagnostic and/or therapeutic gene in neuroblastoma and other malignancies.

\section{MATERIALS AND METHODS}

\section{Cell lines, culture conditions, and reagents.}

The lines SH-EP [40], CEM-C7H2 [41] and Phoenix $^{\mathrm{TM}}$ packaging cells [42] were cultured in RPMI1640 (Lonza, Basel, Switzerland) containing $10 \%$ fetal calf serum, $100 \mathrm{u} / \mathrm{ml}$ penicillin, $100 \mu \mathrm{g} /$ $\mathrm{ml}$ streptomycin (PAA, Pasching, Austria) and $2 \mathrm{mM}$ L-glutamine (Lonza, Basel, Switzerland) at 5\% $\mathrm{CO}_{2}$. All cultures were routinely tested for mycoplasma contamination using the Venor ${ }^{\mathrm{R}}$ GeM-mycoplasma detection kit (Minerva Biolabs, Berlin, Germany).

\section{Retroviral vectors and production of retroviruses.}

pLIB-MCS2-iresPuro, pLIB-MCL1-iresPuro pLIB-rtTA-M2-iresTRSID-iresPuro, pQ-tetCMV-BimSV40Neo, pQ-tetCMV-Noxa-SV40Neo, pQ-tetH1-SV40-

C)

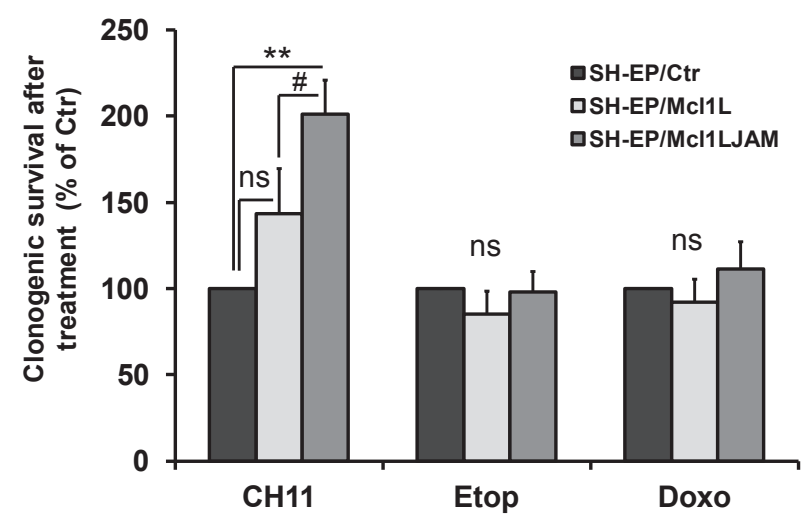

Figure 6: $\mathrm{Mcl1}_{\mathrm{JAM}}$ protects against extrinsic death signalling. SH-EP/Ctr, SH-EP-Mcl1L and $\mathrm{SH}-\mathrm{EP} / \mathrm{Mcl1} \mathrm{L}_{\mathrm{JAM}}$ cells were treated with either $100 \mathrm{ng} / \mathrm{ml}$ FAS-activating CH11 antibody for 0,24 and 48 hours (a) or $0.1 \mu \mathrm{g} / \mathrm{ml}$ recombinant TRAIL for 72 and 96 hours (b) and subjected to PI-FACS analyses. Shown is the mean of three independent experiments. $4 \times 10^{4} \mathrm{SH}-\mathrm{EP} / \mathrm{Ctr}, \mathrm{SH}-\mathrm{EP} / \mathrm{Mcl1L}$ and SH-EP/

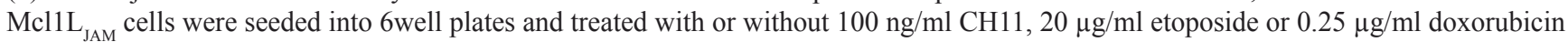
for 72 hours. Surviving cell colonies were fixed and stained with crystal violet/methanol and de-stained with SDS/ethanol. Supernatants were measured photometrically and treated SH-EP/Ctr cells were set as $100 \%$. Shown is the mean of four independent experiments (c). Statistical analysis was performed using students t-test $\left(* * \mathrm{P}<0.01, * * * \mathrm{P}<0.001\right.$ difference between $\mathrm{Ctr}$ and $\mathrm{Mcl} 1 \mathrm{~L}$ or $\mathrm{Mcl}_{1} \mathrm{~L}_{\mathrm{JAM}}$, \# $\mathrm{P}<$ 0.05.difference between $\mathrm{Mcl} 1 \mathrm{~L}$ and $\mathrm{Mcl1L}_{\mathrm{JAM}}$ ). 
Puro have been described before [34, 43, 44]. The coding sequence for $\mathrm{Mcl1}_{\mathrm{JAM}}$ was amplified from human cDNA and inserted into the BamH1-EcoRI sites of pLIB-MCS2iresPuro. For live-cell imaging, the coding sequence of ECFP or EYFP were amplified from pECFP-C1 and pEYFP-C1 (Clontech Laboratories Inc, Mountain View, CA, USA) and inserted into the EcoR1 site of pLIB-Mcl1L-iresPuro (resulting in pLIB-ECFP-Mcl1LiresPuro) or pLIB-Mcl1 $\mathrm{L}_{\mathrm{JAM}}$-iresPuro (resulting in pLIBEYFP-Mcl1L $\mathrm{JAM}$-iresPuro). The production of retrovirus supernatants was described previously [43]. The retroviral supernatants were used to generate SHEP/Ctr, SH-EP/ Mcl1L, SH-EP/Mc11L ${ }_{\text {JAM }}$, SH-EP/ECFP-Mcl1L or SH-EP/ EYFP-Mcl1L $\mathrm{JAM}_{\text {JA }}$ cells. The tetracyclin-regulated cell lines $\mathrm{SH}-\mathrm{EP} /$ tetNoxa and SH-EP/tetBim have been described previously $[34,44]$. These cells lines were further infected with supernatants containing either pLIB-ECFP-Mcl1LiresPuro or pLIB-EYFP-Mcl1L $\mathrm{JAM}$-iresPuro, generating SH-EP/tetNoxa-ECFP-Mcl1L, SH-EP/tetNoxa-EYFP$\mathrm{Mcl1L}_{\mathrm{JAM}}, \mathrm{SH}-\mathrm{EP} /$ tetBim-EYFP- Mcl1L $\mathrm{JAM}_{\text {JA }}$ and SH-EP/ tetBim-ECFP-Mcl1L cells.

\section{Detection of Mcl1L $\mathrm{JAM}_{\mathrm{JA}}$ by PCR.}

$\mathrm{Mcl1L}_{\mathrm{JAM}}$ expression was analysed via RT-PCR. For PCR detection the coding sequence of MCL1 was amplified from cDNA and a nested PCR was performed using 5' AAGAGGAGCTGGACGGGTAC and 3' TGGCTTTGTGTCCTTGGC which amplifies part of the PEST region. PCR products were analysed on $2 \%$ agarose gels.

\section{Immunoprecipitation and Immunoblotting.}

For immuoprecipitation $1 \times 10^{7}$ cells were lysed in PBS containing 1\% IGEPAL, phosphatase- and protease-inhibitors. For immunoprecipitation $1 \mu \mathrm{g}$ of anti-rabbit Bim antibody (Cell Signaling Technology Inc., Boston, MA, USA), $2.5 \mu \mathrm{g}$ of anti-mouse Noxa (Abcam, Cambridge, UK), or mouse or rabbit immunoglobulin, as a negative control, were covalently coupled to Tachisorb ${ }^{\mathrm{TM}}$ Immunoadsorbent (Calbiochem, Nottingham, UK) or AffiPrep Protein A Support (BioRad Laboratories, Munich, Germany) using dimethylpimelidate dihydrochloride/ Borax buffer. Antibody-bead complexes were added to $500 \mu \mathrm{g}$ lysate and incubated at $4^{\circ} \mathrm{C}$ for 6 hours. Tachisorb $^{\mathrm{TM}}$-/Protein A-immunocomplexes were washed four times in PBS/IGEPAL-buffer, resuspended in SDSsample buffer and subjected to SDS-PAGE and blotting. Equal amounts of total-protein and cleared supernatants were loaded as controls. Immunoblot analysis was performed as previously described [45] using primary antibodies directed against human Bim and Mcl1 (BDPharmingen, USA, pMcl1(Ser159/Thr163) and BclxL (Cell Signaling Technology Inc., Boston, USA), Noxa
(Alexis Biochemicals, San Diego, CA, USA), GFP (Sigma, Vienna, Austria) and GAPDH (Acris antibody GmbH, Herford, Germany). The membranes were then washed and incubated with horseradish-peroxidaseconjugated anti-mouse or anti-rabbit secondary antibodies (Amersham Biosciences, Buckinghamshire, UK). The blots were developed by enhanced chemiluminescence (GE-Healthcare, Vienna, Austria) and measured with an AutoChemi detection system. Densitometry analysis was performed using LabWorks software (UVP, Cambridge, UK).

\section{Colony forming assay (CFA).}

To determine the ability of SH-EP cells to form colony units, $2 \times 10^{3}$ cells were seeded into a 6 well and cultured up to 7 days. For chemotherapeutic treatment $4 \times 10^{4}$ cells were seeded into 6 wells and treated for 72 hours with chemotherapeutic agents $(\mathrm{CH} 11$, etoposide, doxorubicin). Afterwards medium was removed and cells were fixed and stained with $0.2 \%$ crystal violet in $50 \%$ methanol. Cell density was measured photometrically after discoloration with $0.5 \% \mathrm{SDS}$ in $50 \%$ ethanol. Untreated/ mock-infected cells were set as $100 \%$.

\section{Flow cytometry analyses.}

Apoptosis was assessed by staining the cells with propidium-iodide (PI) using a CytomicsFC-500 Beckman Coulter as previously described [46]. In short: $2 \times 10^{5}$ cells were harvested and resuspended in hypotonic PI solution for 2-4 hours at $4^{\circ} \mathrm{C}$. Stained nuclei in the sub-G1 marker window were considered to represent apoptotic cells. Statistical analysis was performed using GraphPad Prism 4.0 software.

\section{Live cell fluorescence microscopy.}

For live cell analyses cells were grown on LabTek Chamber Slides ${ }^{\mathrm{TM}}$ (Nalge Nunc International, Rochester, NY, USA) coated with $0.1 \mathrm{mg} / \mathrm{ml}$ collagen. Images were collected with an Axiovert200M microscope with a 63x-oil objective (Zeiss, Vienna, Austria). Mitochondria staining was performed using $300 \mathrm{nM}$ CMXRos (Invitrogen, Carlsbad, USA).

\section{Statistical analysis.}

Statistical significance of differences between controls and treated cells were calculated using unpaired t-test. All statistical analyses were performed using Graph Pad Prism 4.0 software. 


\section{Acknowledgement}

This work was supported by grants from "Kinderkrebshilfe Tirol und Vorarlberg", the "Krebshilfe Südtirol", the "SVP-Frauen-Initiative", the "Kinderkrebshilfe Südtirol-Regenbogen", by the intramural funding program of the Medical University Innsbruck for young scientists MUI-START (P2012032014) and by the MFI funding program of the Medical University Innsbruck (MFI-9400). The Tyrolean Cancer Research Institute and this study are supported by the "Tiroler Landeskrankenanstalten Ges.m.b.H. (TILAK)" and the "Tyrolean Cancer Society".

\section{REFERENCES}

1. Kozopas KM, Yang T, Buchan HL, Zhou P, and Craig RW, MCL1, a gene expressed in programmed myeloid cell differentiation, has sequence similarity to BCL2, Proc.Natl. Acad.Sci.U.S.A 1993 90(8):3516-3520.

2. Day CL, Chen L, Richardson SJ, Harrison PJ, Huang DCS, and Hinds MG, Solution Structure of Prosurvival Mcl-1 and Characterization of Its Binding by Proapoptotic BH3-only Ligands, Journal of Biological Chemistry 2005 280(6):4738-4744.

3. Clohessy JG, Zhuang J, and Brady HJM, Characterisation of Mcl-1 cleavage during apoptosis of haematopoietic cells, British Journal of Haematology 2004 125(5):655-665.

4. Domina AM, Smith JH, and Craig RW, Myeloid Cell Leukemia 1 Is Phosphorylated through Two Distinct Pathways, One Associated with Extracellular Signalregulated Kinase Activation and the Other with G2/M Accumulation or Protein Phosphatase 1/2A Inhibition, Journal of Biological Chemistry 2000 275(28):2168821694.

5. Domina AM, Vrana JA, Gregory MA, Hann SR, and Craig RW, MCL1 is phosphorylated in the PEST region and stabilized upon ERK activation in viable cells, and at additional sites with cytotoxic okadaic acid or taxol, Oncogene 2004 23(31):5301-5315.

6. Zhong Q, Gao W, Du F, and Wang X, Mule/ARF$\mathrm{BP} 1$, a BH3-only E3 ubiquitin ligase, catalyzes the polyubiquitination of Mcl-1 and regulates apoptosis, Cell 2005 121(7):1085-1095.

7. Huang HM, Huang CJ, and Yen JJ, Mcl-1 is a common target of stem cell factor and interleukin-5 for apoptosis prevention activity via MEK/MAPK and PI-3K/Akt pathways, Blood 2000 96(5):1764-1771.

8. Le Gouill S, Podar K, Amiot M, Hideshima T, Chauhan D, Ishitsuka K, Kumar S, Raje N, Richardson PG, Harousseau $\mathrm{JL}$, and Anderson KC, VEGF induces Mcl-1 up-regulation and protects multiple myeloma cells against apoptosis, Blood 2004 104(9):2886-2892.

9. Wang JM, Chao JR, Chen W, Kuo ML, Yen JJ, and Yang-
Yen HF, The antiapoptotic gene mcl-1 is up-regulated by the phosphatidylinositol 3-kinase/Akt signaling pathway through a transcription factor complex containing CREB, Mol.Cell Biol. 1999 19(9):6195-6206.

10. Ding Q, Huo L, Yang JY, Xia W, Wei Y, Liao Y, Chang CJ, Yang Y, Lai CC, Lee DF, Yen CJ, Chen YJR, Hsu JM, Kuo HP, Lin CY, Tsai FJ, Li LY, Tsai CH, and Hung MC, Down-regulation of Myeloid Cell Leukemia-1 through Inhibiting Erk/Pin 1 Pathway by Sorafenib Facilitates Chemosensitization in Breast Cancer, Cancer Research 2008 68(15):6109-6117.

11. Inoshita S, Takeda K, Hatai T, Terada Y, Sano M, Hata J, Umezawa A, and Ichijo H, Phosphorylation and inactivation of myeloid cell leukemia 1 by JNK in response to oxidative stress, J.Biol Chem 2002 277(46):43730-43734.

12. Morel C, Carlson SM, White FM, and Davis RJ, Mcl-1 Integrates the Opposing Actions of Signaling Pathways That Mediate Survival and Apoptosis, Molecular and Cellular Biology 2009 29(14):3845-3852.

13. Maurer U, Charvet C, Wagman AS, Dejardin E, and Green DR, Glycogen synthase kinase- 3 regulates mitochondrial outer membrane permeabilization and apoptosis by destabilization of MCL-1, Mol.Cell 2006 21(6):749-760.

14. Cuconati A, Mukherjee C, Perez D, and White E, DNA damage response and MCL-1 destruction initiate apoptosis in adenovirus-infected cells, Genes Dev. 2003 17(23):29222932.

15. Willis SN, Chen L, Dewson G, Wei A, Naik E, Fletcher JI, Adams JM, and Huang DC, Proapoptotic Bak is sequestered by $\mathrm{Mcl}-1$ and $\mathrm{Bcl}-\mathrm{xL}$, but not Bcl-2, until displaced by BH3-only proteins, Genes Dev. 2005 19(11):1294-1305.

16. Clohessy JG, Zhuang J, de Boer J, Gil-Gomez G, and Brady HJ, Mcl-1 interacts with truncated Bid and inhibits its induction of cytochrome c release and its role in receptormediated apoptosis, J.Biol.Chem. 2006 281(9):5750-5759.

17. Czabotar PE, Lee EF, van Delft MF, Day CL, Smith BJ, Huang DCS, Fairlie WD, Hinds MG, and Colman PM, Structural insights into the degradation of Mcl-1 induced by BH3 domains, Proceedings of the National Academy of Sciences 2007 104(15):6217-6222.

18. Gomez-Bougie P, Ménoret E, Juin P, Dousset C, PellatDeceunynck $\mathrm{C}$, and Amiot $\mathrm{M}$, Noxa controls Muledependent Mcl-1 ubiquitination through the regulation of the Mcl-1/USP9X interaction, Biochemical and Biophysical Research Communications 2011 413(3):460-464.

19. Gomez-Bougie P, Oliver L, Le Gouill S, Bataille R, and Amiot M, Melphalan-induced apoptosis in multiple myeloma cells is associated with a cleavage of Mcl-1 and Bim and a decrease in the Mcl-1/Bim complex, Oncogene 2005 24(54):8076-8079.

20. Wuilleme-Toumi S, Trichet V, Gomez-Bougie P, Gratas C, Bataille R, and Amiot M, Reciprocal protection of Mcl-1 and Bim from ubiquitin-proteasome degradation, Biochem. Biophys.Res.Commun. 2007 361(4):865-869. 
21. Herrant M, Jacquel A, Marchetti S, Belhacene N, Colosetti P, Luciano F, and Auberger P, Cleavage of Mcl-1 by caspases impaired its ability to counteract Bim-induced apoptosis, Oncogene 2004 23(47):7863-7873.

22. Ding Q, He X, Hsu JM, Xia W, Chen CT, Li LY, Lee DF, Liu JC, Zhong Q, Wang X, and Hung MC, Degradation of Mcl-1 by betaTrCP Mediates Glycogen Synthase Kinase 3-Induced Tumor Suppression and Chemosensitization, Molecular and Cellular Biology 2007 27(11):4006-4017.

23. Inuzuka H, Shaik S, Onoyama I, Gao D, Tseng A, Maser RS, Zhai B, Wan L, Gutierrez A, Lau AW, Xiao Y, Christie AL, Aster J, Settleman J, Gygi SP, Kung AL, Look T, Nakayama KI, DePinho RA, and Wei W, SCFFBW7 regulates cellular apoptosis by targeting MCL1 for ubiquitylation and destruction, Nature 2011 471(7336):104109.

24. Schwickart M, Huang X, Lill JR, Liu J, Ferrando R, French DM, Maecker H, O'Rourke K, Bazan F, EasthamAnderson J, Yue P, Dornan D, Huang DCS, and Dixit VM, Deubiquitinase USP9X stabilizes MCL1 and promotes tumour cell survival, Nature 2010 463(7277):103-107.

25. Han J, Goldstein LA, Gastman BR, and Rabinowich H, Interrelated Roles for Mcl-1 and BIM in Regulation of TRAIL-mediated Mitochondrial Apoptosis, J.Biol Chem 2006 281(15):10153-10163.

26. Weng C, Li Y, Xu D, Shi Y, and Tang H, Specific cleavage of Mcl-1 by caspase-3 in tumor necrosis factor-related apoptosis-inducing ligand (TRAIL)-induced apoptosis in Jurkat leukemia T cells, J.Biol Chem 2005 280(11):1049110500 .

27. Bae J, Leo CP, Hsu SY, and Hsueh AJW, MCL-1S, a Splicing Variant of the Antiapoptotic BCL-2 Family Member MCL-1, Encodes a Proapoptotic Protein Possessing Only the BH3 Domain, Journal of Biological Chemistry 2000 275(33):25255-25261.

28. Bingle CD, Craig RW, Swales BM, Singleton V, Zhou $\mathrm{P}$, and Whyte MKB, Exon Skipping in Mcl-1 Results in a Bcl-2 Homology Domain 3 Only Gene Product That Promotes Cell Death, Journal of Biological Chemistry 2000 275(29):22136-22146.

29. Boise LH, González-García M, Postema CE, Ding L, Lindsten T, Turka LA, Mao X, Nuñez G, and Thompson $\mathrm{CB}$, bcl-x, a bcl-2-related gene that functions as a dominant regulator of apoptotic cell death, Cell 1993 74(4):597-608.

30. Kim JH, Sim SH, Ha HJ, Ko JJ, Lee K, and Bae J, MCL$1 \mathrm{ES}$, a novel variant of MCL-1, associates with MCL-1L and induces mitochondrial cell death, FEBS Letters 2009 583(17):2758-2764.

31. Fujise K, Zhang D, Liu Jl, and Yeh ETH, Regulation of Apoptosis and Cell Cycle Progression by MCL1, Journal of Biological Chemistry 2000 275(50):39458-39465.

32. Jamil S, Sobouti R, Hojabrpour P, Raj M, Kast J, and Duronio V, A proteolytic fragment of Mcl-1 exhibits nuclear localization and regulates cell growth by interaction with Cdk1, Biochem.J. 2005 387(Pt 3):659-667.

33. Thomas LW, Lam C, and Edwards SW, Mcl-1; the molecular regulation of protein function, FEBS Letters 2010 584(14):2981-2989.

34. Hagenbuchner J, Ausserlechner MJ, Porto V, David R, Meister B, Bodner M, Villunger A, Geiger K, and Obexer $\mathrm{P}$, The anti-apoptotic protein BCL2L1/Bcl-xL is neutralized by pro-apoptotic PMAIP1/Noxa in neuroblastoma, thereby determining bortezomib sensitivity independent of prosurvival MCL1 expression, J.Biol.Chem. 2010 285(10):6904-6912.

35. Warr MR, Acoca S, Liu Z, Germain M, Watson M, Blanchette M, Wing SS, and Shore GC, BH3-ligand regulates access of MCL-1 to its E3 ligase, FEBS Lett. 2005 579(25):5603-5608.

36. Mei Y, Du W, Yang Y, and Wu M, Puma(*)Mcl-1 interaction is not sufficient to prevent rapid degradation of Mcl-1, Oncogene 2005 24(48):7224-7237.

37. Thomas LW, Lam C, Clark RE, White MRH, Spiller DG, Moots RJ, and Edwards SW, Serine 162, an Essential Residue for the Mitochondrial Localization, Stability and Anti-Apoptotic Function of Mcl-1, PLoS One 2012 7(9):e45088-

38. Obexer P, Geiger K, Ambros PF, Meister B, and Ausserlechner MJ, FKHRL1-mediated expression of Noxa and Bim induces apoptosis via the mitochondria in neuroblastoma cells, Cell Death Differ 2007 14(3):534-547.

39. Weng C, Li Y, Xu D, Shi Y, and Tang H, Specific cleavage of Mcl-1 by caspase-3 in tumor necrosis factor-related apoptosis-inducing ligand (TRAIL)-induced apoptosis in Jurkat leukemia T cells, J.Biol.Chem. 2005 280(11):1049110500 .

40. Geiger K, Hagenbuchner J, Rupp M, Fiegl H, Sergi C, Meister B, Kiechl-Kohlendorfer U, Muller T, Ausserlechner MJ, and Obexer P, FOXO3/FKHRL1 is activated by 5-aza-2-deoxycytidine and induces silenced caspase- 8 in neuroblastoma, Mol.Biol.Cell 2012 23(11):2226-2234.

41. Ausserlechner MJ, Salvador C, Deutschmann A, Bodner M, Viola G, Bortolozzi R, Basso G, Hagenbuchner J, and Obexer P, Therapy-resistant acute lymphoblastic leukemia (ALL) cells inactivate $\mathrm{FOXO} 3$ to escape apoptosis induction by TRAIL and Noxa, Oncotarget 2013 online publication1-13.

42. Grignani F, Kinsella T, Mencarelli A, Valtieri M, Riganelli D, Grignani F, Lanfrancone L, Peschle C, Nolan GP, and Pelicci PG, High-efficiency gene transfer and selection of human hematopoietic progenitor cells with a hybrid EBV/ retroviral vector expressing the green fluorescence protein, Cancer Res. 1998 58(1):14-19.

43. Ausserlechner MJ, Obexer P, Deutschmann A, Geiger K, and Kofler R, A retroviral expression system based on tetracycline-regulated tricistronic transactivator/repressor vectors for functional analyses of anti-proliferative and toxic genes, Mol.Cancer Ther. 2006 5(8):1927-1934. 
44. Hagenbuchner J, Kuznetsov A, Hermann M, Hausott B, Obexer $\mathrm{P}$, and Ausserlechner MJ, FOXO3-induced reactive oxygen species are regulated by BCL2L11 (Bim) and SESN3, J.Cell Sci. 2012 125(Pt 5):1191-1203.

45. Obexer P, Hagenbuchner J, Rupp M, Salvador C, Holzner M, Deutsch M, Porto V, Kofler R, Unterkircher T, and Ausserlechner MJ, p16INK4A sensitizes human leukemia cells to FAS- and glucocorticoid-induced apoptosis via induction of BBC3/Puma and repression of MCL1 and BCL2, J.Biol.Chem. 2009 284(45):30933-30940.

46. Hagenbuchner J, Kuznetsov AV, Obexer P, and Ausserlechner MJ, BIRC5/Survivin enhances aerobic glycolysis and drug resistance by altered regulation of the mitochondrial fusion/fission machinery, Oncogene 2012, online publication 